\title{
SUJEITO E INVENÇ̃̃O: A TOPOLOGIA BORROMEANA NA CLÍNICA DAS PSICOSES
}

Andréa Máris Campos Guerra, Ana Cristina Figueiredo, Luciana Luiz Borçato, Pollyana Vieira e Souza, Carolina Suppes Andrada

Andréa Máris Campos
Guerra
Doutora em Teoria
Psicanalítica (UFRJ);
professora da
PUC/MG.
Ana Cristina Figueiredo
Psicanalista;
doutora em Saúde
Coletiva IMS/Uerj;
professora da UFRJ.
Luciana Luiz Borçato
Psicóloga (Fumec)
e pós-graduanda em
Teoria Psicanalítica
(Fafich/UFMG),
ex-bolsista da
Fapemig junto ao
ProPic/Fumec.
Pollyana Vieira e Souza
Psicóloga (Fumec)
e especialista em
Clínica Psicanalítica
nas Instituições de
Saúde (PUC/MG).
Carolina Suppes Andrada
Psicóloga (Fumec);
ex-bolsista da
Funadesp junto ao
ProPic/Fumec.

Andréa Máris Campos

Psicanalítica (UFRJ)

professora da

Psicanalista;

Coletiva IMS/Uerj

Luciana Luiz Borçato

Psicóloga (Fumec)

Teoria Psicanalítica

(

Fapemig junto ao

Pollyana Vieira e Souza

Clínica Psicanalític nas Instituições de

Carolina Suppes Andrada Psicóloga (Fumec); ProPic/Fumec.
RESUMO: A partir dos aportes teóricos de J. Lacan acerca da topologia borromeana na década de 1970, ressaltaremos alguns aspectos do caso do escritor James Joyce como introdução à discussão de um caso clínico de psicose. Trata-se do Profeta Gentileza. Tentaremos demonstrar as estratégias de estabilização adotadas por ele, a partir da 'missão' de pregação recebida como 'aviso astral'. Nessa análise, incluímos o trabalho sobre o significante, a invenção de sua escrita com grafia neológica, a nominação e seus efeitos sobre o gozo. Ensaiaremos uma discussão topológica do caso, demonstrando como a topologia borromeana pode contribuir para a abordagem psicanalítica da psicose.

Palavras-chave: Psicose, criação artística, topologia borromeana, clínica psicanalítica.

ABSTRACT: Subject and invention: the Borromean topology in the clinical approach to psychosis. Based on J. Lacan's theoretical approach to Borromean topology in the seventies decade we emphasize some aspects of the case of James Joyce as an introduction to discuss a clinical case of psychosis known as "Profeta Gentileza". We propose to demonstrate his stabilization strategies which concern his preaching as a 'mission' received through an 'astral sign'. This analysis includes his work upon the signifier, with the creation of a neological writing, his naming as a prophet and its effects on the subject's jouissance. We also engage in a topological discussion about the case demonstrating how Borromean topology can be functional to psychoanalytical practice with psychosis.

Keywords: Psychosis, artistic creation, Borromean topology, psychoanalytic treatment. 


\section{INTRODUÇÃ $0^{1}$}

O conjunto da obra de J. Lacan pode ser interpretado de diferentes maneiras. Sobretudo com os avanços do final de sua obra, temos uma tendência a nos orientar por uma perspectiva que privilegia o a posteriori e, com ela, buscarmos nos textos 'primeiros' os desenvolvimentos ulteriores que 'já estavam lá'. O próprio Lacan respondia a esses intentos dizendo que já era suficiente constatar que o que ele havia enunciado antes não havia impedido o suceder do futuro. E que essa ilusão retrospectiva não seria senão um exemplo da ação retroativa da cadeia do discurso.

De fato, com a topologia dos nós apresentada nos anos 1970, a idéia de sucessão ou deslizamento ganha outro estatuto. É de enlaçamento que começamos, então, a falar. Pensar que o que Lacan propôs ao final da obra já estava lá desde o início, evidencia uma abordagem do significante e da clínica como de algo que produz sentido ou que, ao menos, o busca. Ora, o que Lacan ressalta com a topologia borromeana é exatamente aquilo que escapa ao sentido e que deverá, por isso mesmo, ser bordejado no tratamento analítico de outra maneira. Reconstruir a própria história, simbolizar ou tratar o inconsciente interpretável — o que do sintoma se analisa a partir da cadeia significante - são tópicos característicos do primeiro período de sua obra. O que não torna inexistente, muito pelo contrário, o que do inconsciente resta inanalisável, gozo opaco, resto da operação analítica, com o qual o sujeito deverá inventar uma maneira de lidar, de 'saber-fazer com isso' (savoir-y-faire), ${ }^{2}$ como propõe ao final de seu ensino. Assim, como efeito recolhido da própria clínica, acaba-se por optar por uma ou por outra interpretação dessa obra, quando não por reinterpretar o início do ensino lacaniano pelos aforismos colocados em jogo ao seu final.

'Algo a reparar' ou 'solução a inventar' seriam, resumidamente, os caminhos para se pensar o tratamento na psicose, conforme o que Lacan nos ensinou,

\footnotetext{
${ }^{1}$ Este texto traz alguns resultados parciais da pesquisa da tese de doutorado "A estabilização psicótica na perspectiva borromeana: criação e suplência”, de Andréa Máris Campos Guerra, sob orientação de Ana Cristina Figueiredo, junto ao Programa de Pós-graduação em Teoria Psicanalítica (UFRJ), realizada com bolsa-sanduíche na França, financiada pela Capes. Também apresenta dados da pesquisa "Estabilização e psicose: a psicanálise aplicada ao campo da saúde mental”, financiada pela Funadesp, através do Programa de Iniciação Científica da Universidade Fumec, que envolveu as demais co-autoras deste artigo.

2 O pronome " $y$ ", para o qual não encontramos uma tradução exata em português, não significa diretamente nada, salvo o fato de indicar a referência a um elemento ausente que é então substituído por sua utilização. Para Lacan, a introdução do pronome "y" "quer dizer se desembaraçar, mas este 'y faire' indica que não pegamos verdadeiramente a coisa, resumindo em conceito" (LACAN, 1976-77, lição de 11/01/1977). Há algo que escapa. E é para tentar dar conta disso que escapa que o discurso vem em socorro. Tudo o que se diz a partir do inconsciente participa do equívoco, da debilidade do mental — que se coloca para todos enquanto insuficiência da linguagem.
} 
respectivamente, na década de 1950 (LACAN, 1955-56/1992; 1998, p.537-590) e, posteriormente, na década de 1970 (LACAN, 1974-75; 1975-76/2005; 2003, p.400-447, p. 448-497 e p. 560-566). Essa última clínica tem conseqüências mais pregnantes ou evidentes no tratamento das psicoses, já que, nas neuroses, o sujeito em análise tende a se reconstruir a toda hora, ressignificando sua história, nos moldes do tratamento estruturalista da linguagem desse primeiro período. Este último tratamento é marcado por uma preocupação estruturalista com o Simbólico, sendo em torno do Nome-do-Pai (NP), como significante que organiza a solução neurótica, que o conceito de psicose se desenvolve. O sintoma neurótico, enquanto formação do inconsciente, é tomado como metáfora, estruturada a partir desse significante primordial (NP). A ausência do NP implica na constituição da estrutura psicótica, enquanto os fenômenos psicóticos seriam articulados ao significante real, fora da cadeia, produzidos pela carência do efeito metafórico. Daí a solução psicótica nesse período, apoiada no modelo neurótico, ser pensada enquanto metáfora delirante que faz as vezes da metáfora paterna, na qual o Nome-do-Pai é o operador essencial.

Ao final de sua transmissão, Lacan se ocupa das diferentes e singulares maneiras de amarração dos três registros face à falha estrutural da linguagem $\$$, que se impõe para todos. Trata-se aqui de uma solução positiva em qualquer estrutura clínica, e não mais de um déficit da psicose em relação à neurose. A diferença entre as duas estruturas clínicas consistiria no fato de que o neurótico responderia pela via da função do Nome-do-Pai, enquanto o psicótico pelo ‘não' ao Pai.

A conseqüência dessa virada no ensino lacaniano é que, enquanto para a neurose pode-se fazer uma teoria restringida ao Édipo para se pensar a solução subjetiva, para a psicose é preciso verificar caso a caso como o sujeito produz sua solução modulando a relação entre os três registros. Multiplicam-se, portanto, as possibilidades de saída que funcionarão como direção no tratamento, devendo cada caso ser examinado em sua singularidade. Mostraremos como as soluções psicóticas em Lacan ganham novo estatuto com a formulação topológica do nó borromeu a três, e mesmo com a proposição do nó borromeu a quatro.

Para Lacan, a topologia do nó borromeu não é um modelo, na medida que todo modelo situa-se a partir da substância suposta pelo Imaginário (LACAN, 1974-75, aula de 17/12/1974). “Eu quero dizer que é o nó sozinho que é o suporte concebível de uma relação entre o que quer que seja e o que quer que seja. Se, de um lado, ele é abstrato, o nó deve, entretanto, ser pensado e concebido como concreto" (LACAN, 1975-76/2005, p. 36-37).

Lacan encontra seu desenho no seminário do matemático G. Thibault, que freqüentava nos anos 70 e nos diz que: 
“quando soube desses negócios, do nó borromeano [...] Uma coisa é certa, foi que eu tive a certeza de ser aquilo algo precioso, precioso para mim, para o que tinha a explicar [...] algo provido de uma consistência particular, que faltava ainda ser sustentada, mas que era para mim reconhecível no que eu enunciava desde o início de meu ensino." (LACAN, 1974-75, aula de 18/03/1975)

Ele atribuiu imediatamente os três registros, Real, Simbólico e Imaginário às três rodelas do nó, utilizando-o para mostrar o Real da clínica psicanalítica. Portanto, "o nó não é o modelo, é o suporte. Ele não é a realidade, é o Real. O que quer dizer que, se há distinção entre o Real e a realidade, é o nó, não como modelo" (LACAN, 1974-75, aula de 15/04/1975). Assim, buscando não fetichizar seu manejo, mas usando-o como recurso topológico na clínica, vamos nos valer do nó borromeu aqui como meio para pensar as invenções psicóticas que funcionam como estabilização do delírio e como pacificação do gozo do Outro nessa estrutura clínica.

\section{A topologia do nó borromeano e a psicose}

Por que recorrer à formalização topológica? Lacan reconhece a insuficiência do matema em transmitir integralmente a experiência clínica. De início, propunha que "a formalização matemática é nosso fim, nosso ideal. Por quê? Porque só ela é matema, quer dizer, é capaz de transmitir integralmente" (LACAN, 1972-73/1982, p. 161). Porém, se a formalização matemática é a escrita das pequenas letras, ela só subsiste à condição de que seja lida, falada e, com isso, algo já está de saída perdido. Daí o matema apresentar-se, antes de tudo, como ideal metalinguístico. Daí seu encontro com a topologia dos nós surgir como novo recurso para mostrar como opera a clínica psicanalítica. Rastro de onde podemos partir para forjar uma proposição sobre as soluções que os psicóticos que atendemos podem criar.

Assim, o ideal seria termos em mãos os barbantes ou arames e manusear o nó - , apresentaremos quatro considerações topológicas importantes para nossa discussão. Como aqui se trata de um texto escrito, aplainaremos o nó nessa apresentação para pensar, em seguida, os casos clínicos.

\section{$\left.1^{\circ}\right)$ Nó a três:}

Trata-se de um nó (ou cadeia) na qual: 1) se for solta uma rodela, as outras se desatam; 2) as rodelas estão superpostas e não entrecruzadas; 3) elas estão enodadas de tal forma que duas estejam livres; 4) e fazem existir um buraco. 


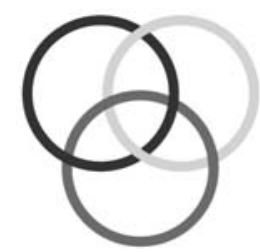

Figura 1 - Nó borromeu de três aros.

O mais importante a destacar é que é do fato de duas rodelas serem livres uma da outra que se suporta a ex-sistência da terceira, especialmente a do Real em relação à liberdade do Simbólico e do Imaginário. A partir do momento em que o Real é enodado borromeanamente aos dois outros registros, eles the resistem. Isso quer dizer que o Real só tem ex-sistência na medida em que encontra no Simbólico e no Imaginário sua parada, seu limite. Daí Lacan afirmar e reafirmar continuamente que o Real não é apenas uma rodela do nó borromeu, mas o efeito da maneira como ele se amarra.

É daí que ele extrai os aportes clínicos que fundamentam o que vem sendo chamado de uma segunda clínica de Lacan ou seu último ensino (MILLER, 2003a). O que importa é essa operação real que, como veremos, desloca o gozo, permitido por uma renomeação do sujeito. Nesse diálogo, portanto, com a matemática e com os matemáticos, Lacan faz nada mais, nada menos que (como sempre) orientar a clínica e reconduzi-la a sua radicalidade.

$\left.2^{\circ}\right)$ Nó a quatro:

É na medida que o Real é um efeito da forma como a amarração se dá — esse efeito de termos rodelas livres e, ao mesmo tempo, atadas - que Lacan propõe um novo nó no qual, de fato, as três rodelas estão livres umas em relação às outras. Elas se encontram apenas sobrepostas. É o quarto elemento, inventado por cada sujeito, que trará a característica borromeana ao nó, concentrando esse efeito real em si mesmo.

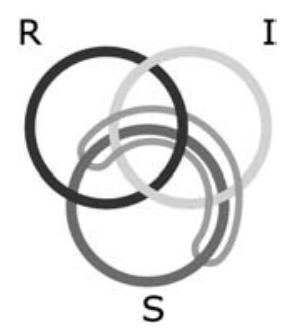

Figura 2 - Nó borromeu de quatro aros com reforço (sinthome) no Simbólico. 
Lacan chega a afirmar que abandona o nó a três, à proporção que não há mais nó, senão enquanto sustentado por esse quarto elemento, por ele denominado sinthome (LACAN, 1975-76/2005, p. 41). ${ }^{3}$ O importante a destacar nessa passagem do nó de três para o nó de quatro aros é a sustentação da amarração por este quarto elemento, podendo qualquer sujeito, a princípio, fabricá-lo. E, em sua repercussão clínica, verificarmos que o Simbólico avançando sobre o Sinthoma (no reforço que forma com ele), pode se estender até certo limite quando, do uso do gozo do sinthoma que resta, o sujeito poderá extrair um savoir-y-faire com esse resto sinthomático. Podemos associar esse resto, que não desaparece, ao rochedo da castração, ao gozo opaco que resta inanalisável, e do qual o sujeito aprenderá a fazer novo uso.

$3^{\circ}$ ) Topologia borromeana da psicose:

Lacan não se decide quanto a um nó para a psicose, avançando em apresentações dessa discussão que, ora o relaciona ao nó de trevo (nó da paranóia), ora ao nó de trevo com um "erro" que exigirá uma suplenciação, ora a um nó a quatro em que Real e Simbólico se encontram entrecruzados e somente o Imaginário livre, tal qual em Joyce. Neste caso, sua obra literária teria forjado um quarto elemento, conferindo ao seu nó, não borromeano, as características borromeanas (LACAN, 1975-76/2005, p. 152).
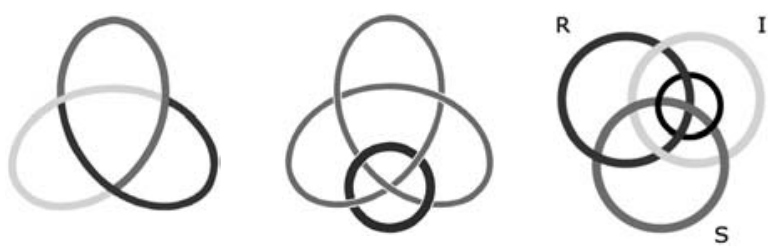

Figura 3 - Nó de trevo (nó da paranóia), nó de trevo com erro (nó trivial), nó joyceano suplenciado.

\footnotetext{
${ }^{3}$ De fato, se esticarmos o nó que o simbólico e o sinthome constituem na amarração borromeana a quatro, eles vão constituir uma única rodela, mas dupla. E esta rodela fará, com o Real e o Imaginário, um nó a três.
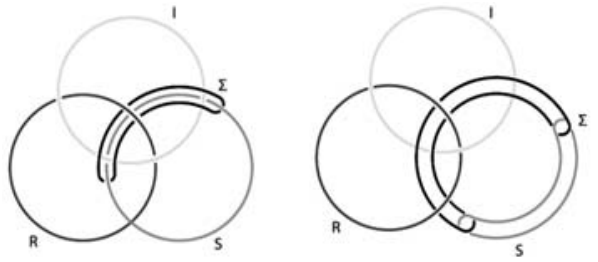

Nós borromeus de quatro aros com reforço no Simbólico, na forma comum e na forma estirada.
} 
$\left.4^{\circ}\right)$ Assim:

O nó borromeu é antes um instrumento para manejo da clínica, que um ideal a ser alcançado segundo uma boa forma que deveria supostamente ganhar para cada sujeito ou para o conjunto dos sujeitos. Não propomos aqui uma "clínica borromeana”, mas antes uma utilização clínica deste recurso topológicomatemático encontrado por Lacan. Além disso, o nó permite pensar os efeitos subjetivos, ao mesmo tempo sobre o significante e sobre o gozo, a partir de sucessivos e diferentes cortes e suturas, operados pelo ato do analista e/ou pelas contingências da própria vida.

É certo, porém, que do nó se destaca exatamente a verificação do efeito real de uma amarração possível que inscreveria o sujeito enquanto sujeito do inconsciente, e também o fato de que essas amarrações (ou invenções) seriam sempre singulares, sem recorrência a um ponto ideal, standard, seja o Édipo, seja a obra, seja qualquer outro elemento.

\section{O caso Joyce: um estilo de suplência a partir da topologia borromeana}

Partindo do estudo de Lacan sobre o escritor James Joyce, discutiremos em seguida um caso no qual o sujeito se faz uma nomeação a partir do trabalho de invenção de uma escrita inaugural. Antes, porém, é necessário precisar alguns termos da hipótese lacaniana sobre Joyce. Em sua discussão, Lacan propõe que foi a escrita joyceana, sua obra literária, o elemento responsável pela invenção de um ego que funcionou como o quarto elemento de sustentação de sua amarração dos três registros. Aponta que não foi qualquer escrita, mas uma que portaria o objeto a - transformando a própria escrita e lhe conferindo uma dimensão fora-do-sentido - , que provocaria efeitos sobre o corpo e sobre o gozo. De fato, Lacan propõe em Joyce a idéia de um artesão que cria um saber-fazer com o sinthoma, enquanto este quarto termo através do qual o sujeito poderia aceder a uma inscrição do gozo, enlaçando assim os três registros.

Nós trabalharemos aqui a partir da idéia lacaniana de que haveria um erro na maneira como os registros se encontram atados em Joyce (LACAN, 197576/2005, p. 151). Ao invés de estarem superpostos (os três registros), o Real (ali denominado sintoma) e o Simbólico fazem uma interpenetração, enquanto o Imaginário resta solto, livre.

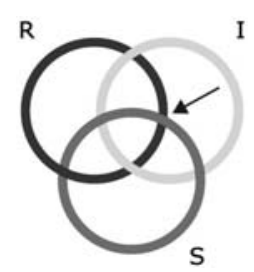

Figura 4 - Erro do nó de Joyce. 
Será o surgimento do 'ego' em Joyce que, fazendo sinthome, inventaria um novo modo de enlaçamento apoiado em sua obra. O 'ego' se escreve em sua obra mais exatamente. Com isso, o Imaginário é enodado no Real e no Simbólico através da existência do quarto termo.

O que interessa para discussão de nosso caso é destacar, no estudo sobre Joyce, a possibilidade de uma invenção que forja uma solução para o sujeito, que apazigua o gozo que o dilacera. Mais do que adentrarmos numa discussão sobre Joyce ser ou não psicótico, buscamos localizar como sua escrita fez nomeação, prescindindo do Nome-do-Pai, e serviu para um uso do sujeito.

Ora, Lacan insiste sobre a importância desse quarto termo em Joyce, pois a maneira como ele se escreve, o efeito real de amarração que provoca, suplencia um desarranjo hipotetizado dos três registros. Se, por algum motivo, estrutural ou contingencial, essa amarração vacila, o quarto elemento pode suplenciar esse ponto, inventando um outro caminho para o sujeito. É daí que nossos recursos clínicos com a psicose podem ser favorecidos.

Assim, a título de sistematização dos termos que utilizamos com referência às saídas na psicose, é importante dizer que entendemos, como termo geral, que inclui qualquer forma de apaziguamento, o vocábulo 'solução' ou 'estabilização'. Ela pode ser precária, como pelo viés da identificação imaginária que forja um eu imaginário para o psicótico. Pode também incluir um trabalho de construção simbólica, como proposto pelas leituras freudiana e lacaniana acerca da metáfora delirante do presidente Schreber. Além disso, pode ser o efeito recolhido no registro do Real por uma passagem ao ato, por exemplo.

Entretanto, nem toda estabilização cria uma forma de amarração dos três registros, podendo ela se desfazer diante de um embate qualquer. Para podermos dizer que há suplência, supomos a invenção de uma nova forma de articulação dos três registros, estejam eles em continuidade, como propõe Lacan para a paranóia, ou não, como propõe para Joyce. O que poderia ser inventada aí seria uma estratégia a partir da qual se produziria uma nova forma de gozo e de articulação entre Real, Simbólico e Imaginário. Trata-se de cortes e suturas que modificam a estrutura do nó, mas que, entretanto, não implicam a existência de um quarto termo que isolaria o efeito real do inconsciente.

Então, poderíamos nos perguntar: toda suplência é uma invenção sinthomática? Provavelmente, não. Miller (2003b), ao trabalhar as invenções psicóticas, destaca na paranóia, na melancolia e na esquizofrenia diferentes operações concernentes a essas invenções, a partir das quais nem todas forjam um sinthoma. O que caracterizaria a nosso ver a invenção sinthomática seria a invenção de um quarto termo, de um elemento a mais, introduzido artificialmente, e que suplencia o erro do nó em questão. Seria, portanto, a invenção de uma ferramenta singular que operaria como nó, evitando o desenlaçamento dos três registros. Ela man- 
teria atados, como quarto elemento, estes registros. Daí Lacan falar de artesão, de artífice do savoir-faire ao se referir à criação deste quarto termo. Poderíamos representar assim a lógica de nossa terminologia, localizando, de fora para dentro: as soluções, as suplências, o sinthoma.

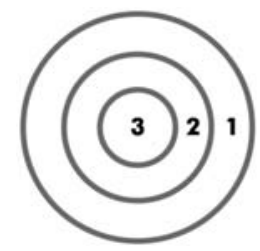

1) Soluções (ou estabilizações); 2) suplência (ou amarrações); 3) sinthoma.

Nós nos valemos da hipótese de que, a partir do trabalho de escrita, a saber, a partir de sua arte ou de seu artifício, Joyce pôde inventar uma maneira de constituir um nó - que fixa a letra de gozo. Lacan situa o que a arte de Joyce tem a ver com o real do inconsciente. Joyce não sabia que ele fazia o sinthoma. Isso era inconsciente. E, por isso, ele era um artífice, um homem de savoir-faire, um artista (LACAN, 1975-76/2005, p. 118). O sinthoma fala de algo que corresponde ao real do inconsciente. É enquanto desabonado do inconsciente que Lacan fala sobre Joyce ser um sinthoma.

Trata-se aqui de um sintoma desabonado, não tributário do aparato semântico que é o inconsciente. Se o abonnement compromete o sujeito a um pagamento adiantado pela recepção de um bem (pelo qual aposta que vai obter — de modo regular, periódico e recorrente - uma recuperação do gozo), o desabono ou a não-subscrição, por outro lado, marca uma ruptura com tal aposta. Trata-se do sintoma em seu puro valor de uso, um uso que vai mais além de seu valor significante e de verdade, quer dizer, um uso desprendido do fantasma, desprendido do gozo extraído da ficção que o sujeito construiu para fazer existir um Outro do gozo fabricado à sua medida. Joyce trabalha diretamente no real da letra. Extrai seu gozo de uma experiência que não é abonada pelo (ou subscrita ao) inconsciente.

Neste ponto um "ego" pôde se escrever. Ego, bem entendido, não como uma versão imaginária e narcísica do eu, pois, como nos diz Lacan sobre Joyce (1975-76/2005, p. 147), "o ego cumpriu nele uma função da qual eu não posso dar conta senão através de meu modo de escrita. [...]. A escrita é essencial a seu ego”. E Jacques Aubert, na Lettre Mensuelle, n.240, coloca em evidência exatamente esse ponto de surgimento do ego na escrita joyceana. Ele o localiza em um texto bem pequeno, escrito antes do Retrato do artista quando jovem, intitulado somente "Retrato do artista". O ato essencial à escritura do ego — que se escreve como "N...ego" neste texto — é a passagem da minúscula à maiúscula. Joyce se apropria desse termo no sentido de 
se fazer um nome próprio, prescindindo do pai. O que conduz Jacques Aubert a interpretar: "Ego nominor Nego", como um ato de nomeação associado à escritura do ego com um "N" antes. "Este artista se inscreve no interior de um gozo inarticulado da voz na lalangue" (AUBERT, 2005, p. 55). É uma nomeação funcionando sobre um traço unário minimal (e, mais ainda, insigne, distintivo), que coloca o ato de nomeação no lugar da letra e que, do fato de que ele está ao mesmo tempo do lado do pronome, do pronominal, introduz uma pluralização de nomes, decorrente da pluralização dos Nomes-do-Pai. Esta construção faz uma ligação entre os principais elementos do gozo disperso em Joyce e vai aparecer, em seu texto, em torno da figura do redentor.

Avançando sobre essas questões, acreditamos poder oferecer elementos para o tratamento de sujeitos psicóticos. E, para discuti-las, apresentaremos um caso de psicose que, utilizando a invenção de uma nova grafia como artifício de criação, conseguiu forjar sua própria solução. Em outras palavras, um caso que conseguiu uma amarração para sustentar um outro modo de gozo.

\section{0 caso do Profeta Gentileza}

José Datrino [da Trindade], nascido em 1917, apresentava desde a infância alguns fenômenos alucinatórios. Porém, como ele vivia em uma família muito religiosa, tais eventos eram interpretados como 'fenômenos espirituais'.

Ele deixou sua cidade natal em torno de 20 anos, casou-se e teve cinco filhos: "três masculinos e dois femininos", como ele dizia. Estabeleceu seus negócios como proprietário de uma empresa de cargas. E tudo isso significou para ele - a posteriori — a execução de uma missão.

Sua vida caminhava bem até o dia em que um senhor o procurou para lhe propor uma sociedade comercial. Ele se colocou todo nu, libertou seus pássaros e mergulhou na argila, dizendo que se tornaria um novo homem ao sair de lá. Mas sua vida cotidiana não se modificou muito. Pensamos que este fato poderia indicar uma convocação simbólica na medida que um nome jurídico exige desdobramento em relação ao nome próprio. Neste caso, a sociedade comercial implicaria na convocação deste outro nome, jurídico, que poderia suscitar em José Datrino uma oposição simbólica ao Nome-do-Pai, que não se encontrava ali inscrito ou suplenciado como quarto elemento.

Será somente após o grande incêndio de um circo numa cidade vizinha à que habitava (Niterói) - no qual morreram mais de 400 pessoas numa tragédia nacional - , que ele receberá a mensagem de um destino a cumprir. Ele tinha, então, em torno de 40 anos. Datrino conta que sentiu uma reação e depois de sete dias antes do Natal, dia 17 de dezembro, recebeu o aviso astral de Deus: 1) de que ele deveria deixar todos os seus negócios materiais para cumprir o desígnio espiritual na Terra; 2) de que deveria vir como São José para apresentar Jesus 
de Nazaré à Terra; 3) e perdoar toda a humanidade, ensinar o perdão e mostrar o caminho da verdade, que é nosso Pai. Já é possível aqui vislumbrar um uso do Pai, certa versão do Pai, ao lado de seu trabalho delirante e de sua criação artística na escrita.

Assim, realizou tudo o que lhe foi destinado. Abandonou a família e os negócios e começou uma vida de peregrinação e de pregação. Durante este período, chegou a ser internado em hospitais psiquiátricos por três vezes, tendo sido diagnosticado como 'paranóico'. Recusou, porém, peremptoriamente, qualquer forma de tratamento. Ele conhecia os caminhos de uma solução mais inventiva e eficaz...

Pouco a pouco, transformou seu nome próprio, forjando uma nomeação a partir do trabalho significante em torno de dois pares binários que ele mesmo estabeleceu: 1) favor-gentileza e 2) obrigado-agradecido. E trabalhou esses significantes na direção de uma transposição da obrigação para a escolha, da dívida para a gentileza, pois Deus quer nossa liberdade, sem nada demandar em troca, gratuitamente.

Acreditamos que aqui se fazem uma primeira produção de sentido e um esboço de amarração do gozo fora-do-sentido. Da experiência com as palavras, José passa a assinar seu nome com a grafia neológica que inventa: Jozze Agradecido. Consegue construir um ponto real de estofo, de limite à significação delirante, conferindo-lhe uma inscrição em torno da qual toda sua existência passará a se consolidar.

Podemos dizer que, onde seu trabalho significante e delirante se escreve, uma nova forma de gozo se organiza, um novo sujeito aparece de um desdobramento na linguagem por ele próprio inventada sob a forma de uma grafia inédita, como veremos logo em seguida. E será exatamente da significação assentada sobre os pares binários aqui referidos que ele destacará e fundará um nome-próprio, escrevendo-se Profeta Gentileza em sua obra.

Paralelamente a esse trabalho com os pares significantes, José Datrino mudou seu nome para Jozze Agradecido e depois para Profeta Gentileza. É ele mesmo quem diz que: “estas duas palavras, 'por gentileza' e 'agradecido', não tem dinheiro que as pague. Elas são minha vida” (GUELMAN, 2000, p. 22). Ele criou verdadeiramente um sistema delirante que se organiza em torno da luta contra o 'capeta-capital' — que está destruindo o mundo - e em torno da defesa do princípio ético da gentileza, de onde se originam todas as demais virtudes, como o amor e a bondade. Muitas vezes ele foi tomado como um mito contemporâneo por denunciar a expropriação do capital e a globalização e por defender um mundo mais humano e justo. Esta é a tese em filosofia de Guelman (2000).

O Profeta viajou durante cerca de 30 anos pelo Brasil, perfazendo um círculo - pois como ele cantava em suas modinhas: "0 circo é redondo, e o mundo é 
arredondado". E, quando mais idoso, sem condições físicas de prosseguir sua missão itinerante, restabeleceu-se no Rio de Janeiro, cidade na qual havia se instalado com a família. Lá pintou 54 pilastras próximas à Rodoviária Grande Rio para manter sua mensagem de pregação.

As pilastras trazem suas mensagens de pregação, escritas com uma grafia absolutamente original. Também porta simbolismos sui generis, como aviões e estrelas entre as palavras, ou o acréscimo de letras nas palavras, que é uma das grandes marcas da escrita de Gentileza, conferindo a elas novas significações, diferentes das em geral partilhadas entre os homens. No caso do AMORRR, por exemplo, temos expressa a figura da Trindade Cristã, manifestada em seu verbo, que traz o R do Pai, o R do Filho e o R do Espírito Santo. Neste caso, o AMORRR implicava no afeto não material. Somente se não fizéssemos um uso material da riqueza, seríamos conduzidos ao uso do AMORRR e da gentileza.

Além disso, as palavras em sua escrita se acomodam numa seqüência de pautas, como as notas musicais numa partitura, sendo o movimento interno do texto assegurado por setas ou pássaros/aviões, que religam as palavras, movimentando o texto internamente, seja remetendo a leitura para a linha seguinte, seja ligando uma palavra à outra, criando uma estética intertextual absolutamente original em sua caligrafia. Interessante também notar a brasilidade como aspecto cultural absorvido por sua estética. Ele alterna, nas pautas de marcação de seu texto, as cores verde e amarela sobre fundo branco, escrevendo suas palavras e signos em azul, e pousando a bandeira nacional ao final da primeira linha de cada escrito no Viaduto.

E, para além desse trabalho artístico (ou artesanal) com as letras e a linguagem na grafia que inaugura, ele promoveu também uma metaforização do corpo, utilizando uma indumentária tão singular quanto sua escrita: vestia uma bata e calçava alpargatas, ambas bordadas por ele mesmo, bem como portava um estandarte pleno de alegorias (como cata-ventos para arejar a cabeça dos homens) e simbolismos com sua mensagem escrita. Com o estandarte em punho, encimado por um punhado de flores que migraram do "Paraíso Gentileza", ele se apresentava como representante de Deus e anunciador de um novo tempo. Seu estandarte parecia funcionar como uma espécie de carteira de identidade mítica.

As pilastras que ele pintou no Rio de Janeiro foram tombadas como patrimônio cultural do município, tendo havido todo um trabalho de restauração das mesmas, que se encontravam perdidas sob a tinta cinza da qual nos fala a cantora Marisa Monte na canção sobre o nosso personagem. Gentileza foi tema de escola de samba com Joãozinho Trinta; foi entrevistado na TV Globo por Jô Soares; e é conhecido por todas as pequenas cidades por onde andou levando sua mensagem, pois se fazia apresentar nas rádios locais ao chegar, convidando a todos para o ouvirem nas praças públicas. Hoje há um número grande de ad- 
miradores seus via internet, em blogs e em várias comunidades no Orkut, sendo todo esse 'sucesso' decorrente de seu reconhecimento como profeta contemporâneo, e não como uma das figuras da loucura.

\section{Discutindo topologicamente o caso}

O que podemos dizer do que faz nomeação neste caso, do que, prescindindo das normas fálica e paterna, pode favorecer a estabilização? O Profeta pode se fazer um novo nome exatamente a partir de sua inscrição entre dois significantes. É entre os elementos dos pares binários criados que nasce o Profeta, sujeito de uma missão e inventor de uma estética singular. Forjada por significantes, letras e símbolos que ganham uma especificidade em sua grafia inédita e em sua prosa exata, talvez possamos dizer que o Profeta nesta invenção conseguiu circunscrever um gozo, do qual antes era parasitário.

Sua escrita comporta, pois, uma caligrafia peculiar que inaugura um novo uso da letra - por ele forjada num abecedário único que civiliza lalíngua. Também confere um novo valor, carregado ou reforçado pela dimensão real do divino, ao texto-nó que esta letra escreve. Ele faz redemoinho com os significantes, ordenados pela lógica singular que ele funda com seus signos, pautas, estruturas gramaticais singularizadas e máximas. A obra, nesse circuito, opera pela ausência de sentido, possibilitando a fixação do gozo. Gentileza dá um destino estético ao excesso de gozo, transformando em obra singular o indizível do real.

Com este corte, faz nascer uma nova possibilidade de costura dos três registros por uma nova amarração. Se supomos que, em seu caso, o Imaginário enlaçava o Simbólico e o Real, dependurados precariamente sem nenhum entrelaçamento entre eles, no momento do desencadeamento teria havido um corte que os teria liberado.

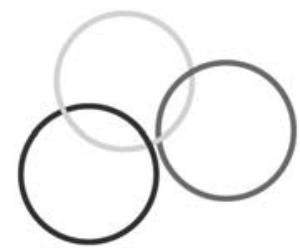

Figura 5 - Nó de José Datrino antes do desencadeamento.

A identificação imaginária (missão de se casar, trabalhar e constituir família) que o sustentava se rompe a partir do convite para compor uma sociedade civil no campo dos negócios. Um novo enlaçamento se inicia quando ele recebe o aviso astral da nova missão que, dessa vez, vem amparada pela construção significante que lhe segue (Imaginário e Simbólico entrelaçados). Além disso, do que resta Real, sem significação, o Profeta faz escrita e invenção, amarrando um gozo pelo nome-missão que a gentileza convoca. Seria o Real enlaçado com o 
outro par - I e S - pelo quarto elemento que inventa com sua grafia original? Não nos parece se tratar de um trabalho que teria se reduzido a um reforço simbólico pela metáfora delirante nem, por outro lado, ao tratamento do real pela obra. Já desencadeada, a psicose encontrando-se declarada, o sujeito corta e remenda, costurando-se um novo modo de ser que envolve todos os registros. Talvez possamos mesmo supor uma invenção sinthomática, o acréscimo artificial de um novo elemento - sua grafia original —, conferindo ao enlaçamento o estatuto de um nó de quatro aros.

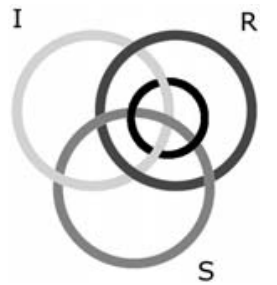

Figura 6 - Possível nó do Profeta Gentileza estabilizado.

Por outro lado, podemos supor também um efeito da obra de Gentileza sobre o laço social no que toca ao endereçamento de sua mensagem, acolhida simbólica e socialmente pelo discurso corrente. Ele se supunha profeta, tendo sido reconhecido como personalidade pública. Ele se fez obra e esta obra foi incorporada pela cidade, a ponto de ter sido tombada como patrimônio cultural de um grande centro urbano do país.

\section{PARA CONCLUIR}

Enfim, o que podemos aprender com estes casos em relação às estabilizações psicóticas? Onde o trabalho delirante de Gentileza se escreve como obra, uma nova forma de gozo fora-do-sentido se organiza e um novo arranjo subjetivo aparece da dobra na linguagem por ele próprio inventada sob a forma de sua caligrafia. Por seu turno, Joyce forja um ego em sua obra, inventando-se em sua escrita. Dessas invenções, de caráter sinthomático, esses sujeitos parecem constituir um savoir-y-faire com o real do inconsciente.

O sujeito, portanto, tem recursos para construir uma ancoragem para o gozo - mas nem sempre e nem para todos de uma mesma maneira. O campo das estabilizações é vasto... O caso que trouxemos nos apresenta, de maneira decisiva, a importância do trabalho singularizado que o período do último ensinamento topológico de Lacan nos orienta a sustentar. Gentileza parece ter conseguido inventar um quarto termo para atar os três registros. Entretanto, é preciso procurar a cada caso o estilo de resposta que o sujeito pode inventar, pois se trata sempre de permitir ao sujeito, psicótico ou não, encontrar um 
novo modo de se escrever. Como diz ainda a cantora do Profeta, Marisa Monte, "todo corpo que tem um deserto tem um olho de água por perto. Para ouvir, basta abrir os poros, para aceitar, basta oferecer".

Recebido em 30/7/2007. Aprovado em 23/8/2007.

\title{
REFERÊNCIAS
}

AUBERT, J. (2005) Ego nominor N...ego. Lettre Mensuelle, numéro spécial 240. Paris: École de la Cause Freudienne, jui.-âou., p. 52-55.

GUELMAN, L. C. (2000) Brasil, tempo de Gentileza. Niterói: Eduff.

GUERRA, A. M. C. (2007) "A estabilização psicótica na perspectiva borromeana: criação e suplência”. Tese de Doutorado, Programa de Pós-graduação em Teoria Psicanalítica, Instituto de Psicologia, Universidade Federal do Rio de Janeiro.

LACAN, J. (1955-56/1992) O Seminário livro 3, As psicoses. Rio de Janeiro: Jorge Zahar.

.(1957-58/1998) "De uma questão preliminar a todo tratamento possível da psicose”, in Escritos. Rio de Janeiro: Jorge Zahar.

.(1970/2003) "Radiofonia", in Outros escritos. Rio de Janeiro: Jorge Zahar.

.(1972/2003) "O aturdito", in Outros escritos. Rio de Janeiro: Jorge Zahar.

.(1972-73/1982) O seminário livro 20, Mais ainda. Rio de Janeiro: Zahar.

.(1974-75/ 1975-76) Le séminaire livre 22, RSI. Ornicar?, n. 2-5.

(1975-76/2005) Le Sémináire livre 23, Le sinthome. Paris: Seuil.

(1976-1977/ 1977-79) Le Séminaire livre 24, L’insu que sait de l'une bévue s'aile à mourre. Ornicar?, n. 12-18.

(1979/2003) "Joyce, o sintoma", in Outros escritos. Rio de Janeiro: Jorge Zahar.

MILLER, J. A. (2003a) O último ensino de Lacan. Op̧̧ão Lacaniana, 35. São Paulo: Eolia, jan., p. 6-24.

(2003b) A invenção psicótica. Opção Lacaniana, 36. São Paulo: Eolia, maio, p. 6-16.

\author{
Andréa Máris Campos Guerra \\ aguerra@uai.com.br \\ Ana Cristina Figueiredo \\ anacrisfigueiredo@gmail.com \\ Luciana Luiz Borçato \\ lucianaborcato@hotmail.com \\ Pollyana Vieira e Souza \\ pollyanavs@yahoo.com.br
}

